\title{
Bioisosteric similarity of drugs in virtual screening
}

\author{
Michael C Hutter ${ }^{*}$, Markus Krier \\ From 5th German Conference on Cheminformatics: 23. CIC-Workshop \\ Goslar, Germany. 8-10 November 2009
}

Choosing compounds for screening is difficult problem due the vast chemical space. The question is thus which compounds are most likely to be hits. The comparison of drugs that all target the same enzyme, however, shows reoccurring chemical modification throughout all therapeutic categories. These so-called bioisosteric replacements [1] comprise simple exchanges of terminal atoms as well as more complex structural modifications, such as ring closures or rearrangements of larger fragments. To detect and evaluate all kinds of replacements we have designed an approach that adopts the algorithmic concept used to assess the homology of amino acid sequences to chemical molecules. The mutual exchange frequencies between distinct atom types are expressed in a substitution matrix [2]. Likewise, pair-wise alignment between the molecules is constructed using dynamic programming [3], with the compounds being represented as unique SMILES. To obtain the actual exchange frequencies, we refined an initial matrix based on observed chemical replacements [4] by collecting the generated alignments of 1353 drugs from 33 therapeutic categories in an automated procedure. To compute the mutual bioisosteric similarity between two molecules a specific function has been derived that makes use of the alignment [5].

To asses the suitability of this bioisosteric similarity for virtual screening, we compared the recovery of known drugs against the background of other substances. The majority of drugs possess a higher similarity within the same class than compared to substances from the ZINC [6] or the Prous Science Drugs of the Future database [7]. Likewise, drugs for the same target are usually recovered at higher values of similarities than compared to other methods based on most common substructure and fingerprint approaches. Moreover, nondrugs without any pharmaceutical function exhibit considerably lower similarities than actual drugs.

Center of Bioinformatics, Saarland University, Building C7.1, D-66041 Saarbrücken, Germany
Furthermore, this bioisosteric similarity can be used to express the chemical diversity within a given compound class. We found that e.g. inhibitors of the HIV Reverse Transcriptase are more divers than Angiotensin-II Antagonists and Tetracycline Antibiotics.

Published: 4 May 2010

\section{References}

1. Patani GA, LaVoie EJ: Chem Rev 1996, 96:3147.

2. Henikoff S, Henikoff JG: Proc Natl Acad Sci USA 1992, 89:10195.

. Smith TF, Waterman MS: J Mol Biol 1981, 147:195.

Sheridan RP: J Chem Inf Comput Sci 2002, 42:103.

Krier M, Hutter MC: J Chem Inf Model 2009, 49:1280.

[http://zinc.docking.org].

[http://pubchem.ncbi.nlm.nih.gov/].

doi:10.1186/1758-2946-2-S1-P18

Cite this article as: Hutter and Krier: Bioisosteric similarity of drugs in virtual screening. Journal of Cheminformatics 2010 2(Suppl 1):P18.

\footnotetext{
Publish with ChemistryCentral and every scientist can read your work free of charge

"Open access provides opportunities to our colleagues in other parts of the globe, by allowing anyone to view the content free of charge." W. Jeffery Hurst, The Hershey Company.

- available free of charge to the entire scientific community

- peer reviewed and published immediately upon acceptance

- cited in PubMed and archived on PubMed Central

- yours - you keep the copyright

Submit your manuscript here:

http://www.chemistrycentral.com/manuscript/

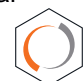
ChemistryCentral
} 